\title{
Phosphorus Recovery from Incinerated Ash of Sewage Sludge by Heat Treatment
}

\author{
Masaaki Takahashi ${ }^{1}$,Yukimasa Takemoto ${ }^{1}$ and Eiji Yuuki ${ }^{2}$ \\ 1. Yokkaichi University, Research Laboratory on Environmental Technology, Kayo-cho 1200, Yokkaichi, Mie 512- 8512, Japan \\ 2. Mie Chuo Kaihatsu Co., Ltd, Hachiya 4713, Yono, Iga, Mie 518-1152, Japan
}

\begin{abstract}
The phosphorus recovery from incinerated ash of sewage sludge by a heat treatment method was investigated. The incinerated ash of sewage sludge was mixed with sodium hydroxide or sodium carbonate, and treated at $750{ }^{\circ} \mathrm{C}$ to $900{ }^{\circ} \mathrm{C}$ in aerobic conditions. The phosphorus was successfully recovered as an alkali metal phosphate from the treated ash through water extraction. The recovery rate of the phosphorus reached about $74 \%$ to $78 \%$. The optimal condition of the phosphorus recovery and composition of the recovered phosphorus was investigated.
\end{abstract}

Key word: Incinerated ash, sewage sludge, sodium hydroxide, sodium carbonate, phosphorus recovery.

\section{Introduction}

Sewage sludge contains significant amounts of phosphorus, and in order to recover phosphorus, some methods were investigated with the incinerated ash or charcoal of the sludge using acid [1] or alkal [2]. The phosphorus in the sludge is considered to exist in many forms of phosphate compounds $\left(\mathrm{AlPO}_{4}, \mathrm{FePO}_{4}\right.$, $\mathrm{Ca}_{3}\left(\mathrm{PO}_{4}\right)_{2}$, etc.) [3]. In an acidic treatment, almost all of the phosphorus can be extracted, however, the recovered phosphorus contains high amounts of aluminum [4-6] which is considered to be inconvenient for the usage of the recovered phosphorus, and finding the usage is needed. On the contrary, the alkali treatment can possibly recover the phosphorus with the low content of aluminum, but the extraction rate is low because of low solubility of the $\mathrm{Ca}_{3}\left(\mathrm{PO}_{4}\right)_{2}$ component of the sludge in alkali conditions [7]. In order to obtain the high extraction rate through the alkali treatment, phosphorus extraction at high temperatures is regarded to be effective [8, 9]. We investigated phosphorus recovery from the charcoal of sewage sludge using $\mathrm{NaOH}$ [10]

Corresponding author: Masaaki Takahashi, researcher, research field: environmental technology. or $\mathrm{Na}_{2} \mathrm{CO}_{3}$ through the heat treatment of the incinerated ash of sewage sludge.

\section{Methods}

\subsection{Recovery Method}

The ash of sewage sludge which was incinerated by an incinerator at $850{ }^{\circ} \mathrm{C}$ in anaerobic condition, was used. The chemical composition is shown in Table 1. As alkali materials, reagents of $\mathrm{NaOH}$ or $\mathrm{Na}_{2} \mathrm{CO}_{3}$ were used.

In the case of $\mathrm{NaOH}$, the aqueous solution of the $\mathrm{NaOH}$ was mixed with the raw ash, and treated at an appropriate temperature $\left(750^{\circ} \mathrm{C}\right.$ [11]) for 1 hour after drying at $105^{\circ} \mathrm{C}$. Later, in order to extract the alkali metal phosphate which is formed through the heat treatment, washing water was added to the treated mixture with $\mathrm{S} / \mathrm{L}$ (solid/liquid) ratio 1:10, and filtrated using filter paper (5A, Toyo Roshi Kaisha, Ltd. Advantec). The phosphorus was recovered from the filtrate by drying at $105{ }^{\circ} \mathrm{C}$ as shown in Fig. 1. The case of $\mathrm{Na}_{2} \mathrm{CO}_{3}$, powder of the $\mathrm{Na}_{2} \mathrm{CO}_{3}$ was mixed with ash, and treated also at $900{ }^{\circ} \mathrm{C}$ [12] for 1 hour, later, washing water was added to the treated mixture, and the phosphorus was recovered the same as with the $\mathrm{NaOH}$. 
Table 1 Chemical composition of the ash.

\begin{tabular}{llllllll}
\hline Element & $\mathrm{Na}_{2} \mathrm{O}$ & $\mathrm{Al}_{2} \mathrm{O}_{3}$ & $\mathrm{SiO}_{2}$ & $\mathrm{P}_{2} \mathrm{O}_{5}$ & $\mathrm{CaO}$ & $\mathrm{Fe}_{2} \mathrm{O}_{3}$ & Others \\
\hline Content (\%) & 1.0 & 6.9 & 31.3 & 18.0 & 14.5 & 18.3 & 10.0 \\
\hline
\end{tabular}

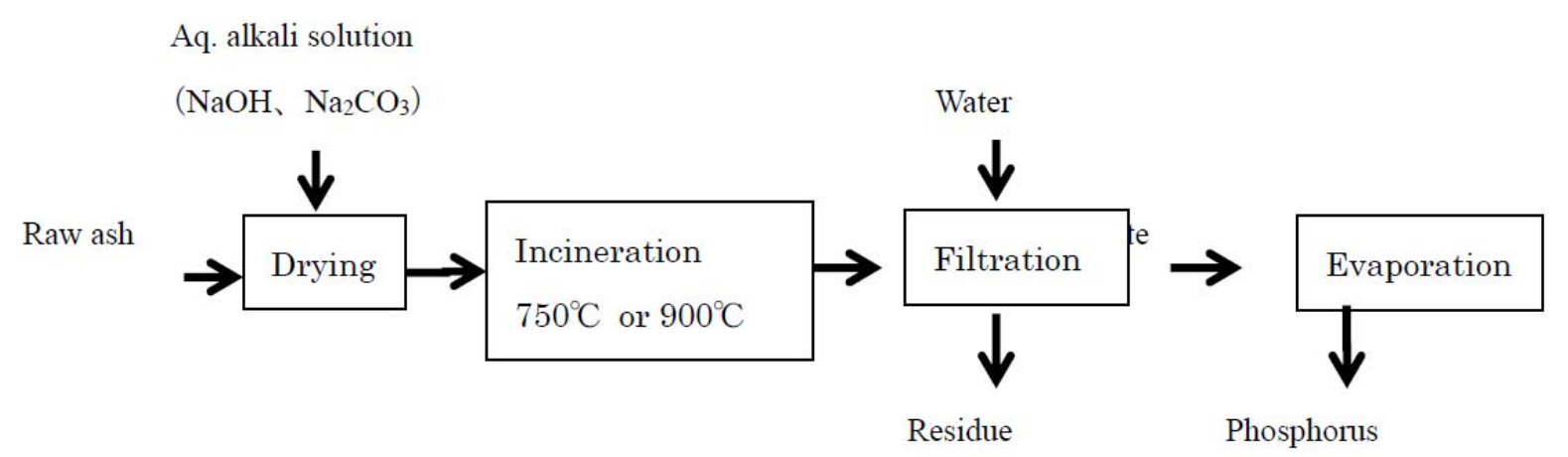

Fig. 1 Recovery method.

\subsection{The Alkali Addition Rate}

In order to decide an optimal addition rate of the alkali, $5 \mathrm{~g}$ of the raw ash was mixed with some concentrations of the aqueous solution of $\mathrm{NaOH}$ or the powder of $\mathrm{Na}_{2} \mathrm{CO}_{3}$. The mixture was dried at $105^{\circ} \mathrm{C}$, and treated at the temperature as mentioned, in aerobic conditions. To extract the phosphorus, water was added to the treated mixture, and was filtrated using filter paper. The phosphorus was recovered from the filtrate by drying at $105{ }^{\circ} \mathrm{C}$ as residue, and the chemical composition was examined using an X-ray analyzer (Rigaku Cooperation SPECTRO XEPOS). The phosphorus content of the residue was degreased by the extraction of the phosphorus, and the degreased amount of the phosphorus tended to be increased with the addition rate of the alkali. The degreasing rate of the phosphorus in the treated ash tends to flatter when the addition rate reached $2 \mathrm{~g}$ (in the case of $\mathrm{NaOH}$, shown in Fig. 2) or $3 \mathrm{~g}$ (in the case of $\mathrm{Na}_{2} \mathrm{CO}_{3}$, shown in Fig. 3). From the result, we decided the optimal addition rate of the alkali for the phosphorus recovery was as follows.

The addition rate: $5 \mathrm{~g}$ of the ash to $3 \mathrm{~g}$ to $4 \mathrm{~g}$ of $\mathrm{NaOH}$, and $5 \mathrm{~g}$ of $\mathrm{Na}_{2} \mathrm{CO}_{3}$.

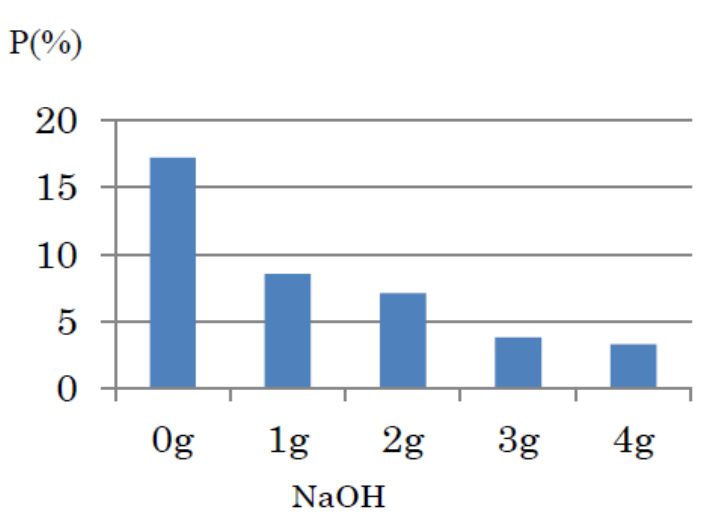

Fig. 2 The relation between the amount of phosphorus in the residue and the $\mathrm{NaOH}$ addition rate.

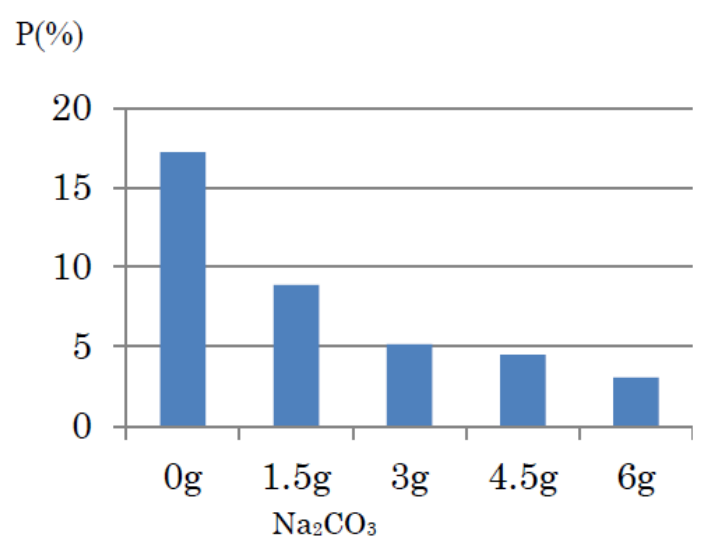

Fig. 3 The relation between the amount of phosphorus in the residue and the $\mathrm{Na}_{2} \mathrm{CO}_{3}$ addition rate. 


\section{Results and Discussion}

In order to confirm the phosphorus recovery, the aq. solution of $\mathrm{NaOH}$ ( $6 \mathrm{~g}$ of $\mathrm{NaOH}$ mixed with $17 \mathrm{~mL}$ of water) was added to the $10 \mathrm{~g}$ of raw ash, and treated as described. Later, $200 \mathrm{~mL}$ of water was added to the treated mixture, and was filtrated using filter paper. The $\mathrm{pH}$ of the filtrate reached about 12 . The possibility of $\mathrm{Cr}^{6+}$ formations through incineration or heat treatment is reported $[13,14]$. In order to confirm the formation of the $\mathrm{Cr}^{6+}$ through this treatment, concentration of the $\mathrm{Cr}^{6+}$ was checked by a simple analysis (using the PACKTEST, KYORITSU Co. $\mathrm{Ltd}), 2 \mathrm{mg} / \mathrm{L}$ of the $\mathrm{Cr}^{6+}$ was detected. The filtrate and residue were dried for analysis at $105{ }^{\circ} \mathrm{C}$, and recovered.

The same experiment was carried out using $10 \mathrm{~g}$ of the ash and $10 \mathrm{~g}$ of $\mathrm{Na}_{2} \mathrm{CO}_{3}$. The small amount of $\mathrm{Cr}^{6+}$ (0.5 mg/L) was found in the filtrate, and phosphorus or residue was recovered.

The amounts of the raw ash and recovered materials are shown in Table 2, and these materials were analyzed using an X-ray analyzer (as shown in Fig. 4). Almost all of the phosphorus was removed from the ash, and the recovery rate was calculated from the material balances and the compositional change as Eq. (1). The recovery rate is considered to be $78 \%$ (in the case of $\mathrm{NaOH}$ ) or $74 \%$ (in the case of $\mathrm{Na}_{2} \mathrm{CO}_{3}$ ).

The recovered phosphorus is considered mainly to be a sodium phosphate from the chemical composition and previous researches, and contains a small amount of aluminum or silicon compounds.

In this treatment, almost the same amount of the treated ash will be remained, and finding the usage of the treated ash is a very important matter. The alkali metal aluminum silicate contained in the residue has a chemical composition like zeolite [15], and the residue is expected to have an ability like zeolite, however, further investigation will be needed in order to find a usage for them. The other matter, formation of the $\mathrm{Cr}^{6+}$ compounds was found, and elimination of them is necessary.

$$
\mathrm{R}=(1-\mathrm{P} 1 \times \mathrm{W} 1 / \mathrm{P} 2 \times \mathrm{W} 2) 100
$$

$\mathrm{R}$ : Phosphorus recovery rate (\%)

Table 2 The amount of the recovered materials (raw ash: $10 \mathrm{~g}$ ).

\begin{tabular}{llll}
\hline Used alkali & Addition rate of the alkali & Amount of the treated ash & Amount of the recovered phosphorus \\
\hline $\mathrm{NaOH}$ & $6 \mathrm{~g}$ & $11.6 \mathrm{~g}$ & $8.2 \mathrm{~g}$ \\
$\mathrm{Na}_{2} \mathrm{CO}_{3}$ & $10 \mathrm{~g}$ & $12.3 \mathrm{~g}$ & $12.1 \mathrm{~g}$ \\
\hline
\end{tabular}

Composition (\%)

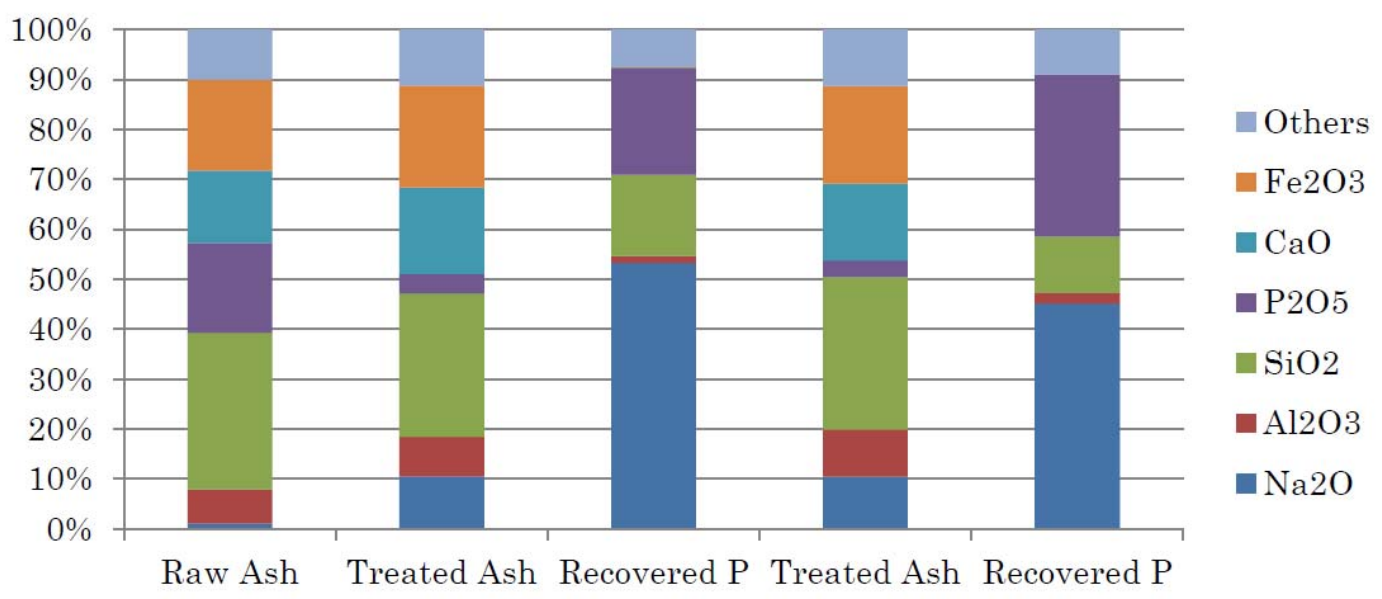

Fig. 4 The composition of the recovered materials. 
P1: Phosphorus concentration of the treated ash

P2: Phosphorus concentration of the raw ash

W1: Amount of the treated ash

W2: Amount of the raw ash

\section{Conclusion}

Phosphorus was recovered from the ash of sewage sludge with a high recovery rate through heat treatment by the addition of alkali metal compounds. Almost all of the recovered phosphorus is considered to be alkali metal phosphate which can be used in many ways. However, much investigation will be needed to determine the best method for practical usage.

\section{Acknowledgements}

The authors wish to express their appreciation to the Hinaga Wastewater Treatment Center (Yokkaichi City Government, Waterworks and Sewage Bureau) who offered us the ash, and also to Dr. Eric Bray (Professor of Yokkaichi University) for his advice on making the article.

\section{References}

[1] Hiroshisa, S., and Masaaki, T. 1997. Gekkan Water, 36-40. (in Japanese)

[2] Keiko, Y., Takahashi, Y., and Hatano, M. 2001. "The Experiment on the Recovering Sodium Phosphate from Incinerated Ash of Sewage Sludge.” In Proceedings of 12th Annual conference of the Japanese Society of Waste Management Expert, 280-1.

[3] Yousuke, N., Msanori, O., Sinsuke, H., and Daisuke, O. 2018. "Chemical Composition of Night Soil Sludge Incineration Ash and the Elution of Phosphate.” Journal of Environmental Chemistry 28 (4): 127-39.

[4] Ingham, J., Ryan, J., Keyakida, E., and Ri, J. 1996. "Phosphorus and Metal Recovery from Sewage Treatment Sludge." In Proceedings of the 7th Annual Conference of the Japan Society of Waste Management Expert, 280-2. (in Japanese)

[5] Masaki, T., Susumu, K., Hiroshisa, S., Eiji, S., Takao, I., Seiji, H., and Hideo, M. 2004. "Technique for Recovering Phosphorus Salt from Incinerated Ash of
Sewage Treatment Sludge." Transactions of Materials Research Society of Japan 29 (5): 2149-52.

[6] Masaaki, T., Susumu, K., Hiroshisa, S., Eiji, S., Takao, I., Seiji, H., and Hideo, M. 2001. "Technology for Recovering Phosphorus from Incinerated Wastewater Treatment Sludge.” Chemosphere 44: 23-9.

[7] Sugawara, R., Abe, T., Sato, K., Moriya, Y., and Hatsuyama, S. 2018. "Hai alkali riyo niyoru rinn kaisyuu zissyou siken oyobi rinn kaisyuu plant kadou kosuto sisan.” (Phosphorus Recovery Test Using a Waste Alkali Materials and Running Cost Estimation of the Recycle Plant) Accessed Oct. 5th 2018. https://www.jstage.jst.go.jp/article/jsmcwm/23/0/23_311/ _pdf.

[8] Masaaki, T., Kunuhiko, S., Susumu, K., and Hideo, E. 2004. "Technique for Recovering Sodium Phosphate from Ash of Sewage Sludge.” In Proceedings of the Sixth International Conferees on Ecobalance, 629-32.

[9] Kunihiko, S., Masaaki, T., Yasuo, O., Susuymu, K., and Hideo, E. 2004. “A Technique for Recovering Sodium Phosphate from Incinerated Ash of Sewage Treatment Sludge by Hydrothermal Synthesis.” Transaction of the material research society of Japan 29 (5): 2021-4.

[10] Masaaki, T., Yukimasa, T., Eiji, Y., and Koichi, S. 2018. "Phosphorus Recovery from Charcoal of Sewage Sludge by Incineration Treatment.” Journal of material science and engineering A 8 (3-4): 59-64.

[11] Masaaki, T., Kunihiko, S., and Keisuke, N. 2005. "Recovery of Phosphate Salt from Charcoal of Sewage Sludge." In Proceedings of the 15th Annual Conference of the Japan Society of Waste Management Expert, 386-8. (in Japanese)

[12] Masaaki, T., Kunuhiko, S., Susumu, K., and Hideo, E. 2004. "Technique for Recovering Phosphorus Salt from Incinerated Ash of Sewage Sludge.” Journal of Advanced Science 16 (2): 66-70.

[13] Masaaki Takahashi, Y. 2015. "Takemoto: Formation of $\mathrm{Cr}^{+6}$ through Drying Processes.” Journal of Material Science A 5 (5-6): 230-2. (in Japanese)

[14] Kouichi, S., and Sadao, Y. "Surveillance Study to Recycle Wood Pellet Combustion Ash Properly and Safely." Annual Report of Kochi Prefectural Environmental Research Center 26: 17-23. (in Japanese)

[15] Hro-o, T., and Takashi, T. Zeolite Science and Technology-Application for Development of Natural Resources, Accessed Apr. 2nd 2018. https://www.jstage.jst.go.jp/article/shigentosozai1989/10 7/1/107_1_2/_pdf. 